cause organized growth and make offspring conform to the type of their parents. Were the bildungstrieb and its successors reduced to the physical, or were they eliminated as the false posits of an erroneous theory? Neither description is useful. These constructs certainly fell into disrepute among late nineteenth-century embryologists, but the genecentred accounts of growth and heredity that are now conventional are closer to the views of von Baer than to those of the later, materialist proponents of 'developmental mechanics'.

The debate over vitalism has become an episode in intellectual history that can only be adequately understood in the light of the conceptual possibilities and the potential for practical research that were available in the early nineteenth century. Similarly, I suspect that we will neither 'solve' the problem of consciousness, nor 'eliminate' consciousness in favour of some superior and incommensurable way of conceptualizing the same phenomenon. Rather, our successors will look back across an intellectual gulf, parodying our conception of consciousness in their undergraduate textbooks and being corrected by more sensitive professional historians.

John Cornwell is to be congratulated on the editing of this collection, which forms an effective introduction to consciousness studies. The papers have been rewritten since the conference at which they were presented to form a more coherent whole, and make frequent reference to one another. Cornwell's introduction is excellent, and includes a summary of the history of consciousness studies. Margaret Boden organizes a clear discussion of the prospects for a science of consciousness around Jerry Fodor's claim that "nobody has the slightest idea how anything material could be conscious". Searle organizes an equally useful discussion around a series of fallacious arguments against a science of consciousness.

The philosopher of quantum mechanics Jeremy Butterfield provides a rigorous introduction to current philosophical ideas on reduction, supervenience and the definitions of materialism and physicalism. $\mathrm{He}$ examines ways in which quantum theory might challenge the physicalist assumptions on which most discussions of the mind/body problem are predicated. Readers unacquainted with the apparatus of contemporary metaphysics, however, may find this paper hard going.

Stephen Rose's lucid discussion of the pitfalls of neurogenetic determinism may seem less relevant to consciousness studies than some of the other papers, but a small slip in Olaf Sporns' introduction to the 'neural Darwinist' approach to the brain shows that Rose's theme is as relevant here as in other areas of psychobiology. Sporns explains that the term 'epigenetic' means "literally 'after' or 'over' the genes". But the use of this term in

\section{Getting to know you}

The bonobo (Pan paniscus), the fourth living species of great ape along with chimpanzees, gorillas and orangutans, was discovered by science little more than 60 years ago, and our knowledge of this gentle animal, which lives naturally only in remote areas of Zaire, is a fraction of that of the other three species. Bonobo: The Forgotten Ape (University of California Press, \$24.95.

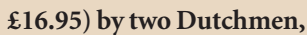
laboratory ethologist Frans de Waal and photographer Frans Lanting, distils the information gathered by the few workers in the field, among them the Japanese primatologists Takayoshi Kano and Suehisa Kuroda (for a review by William McGrew see Nature 387, 142-143; 1997).

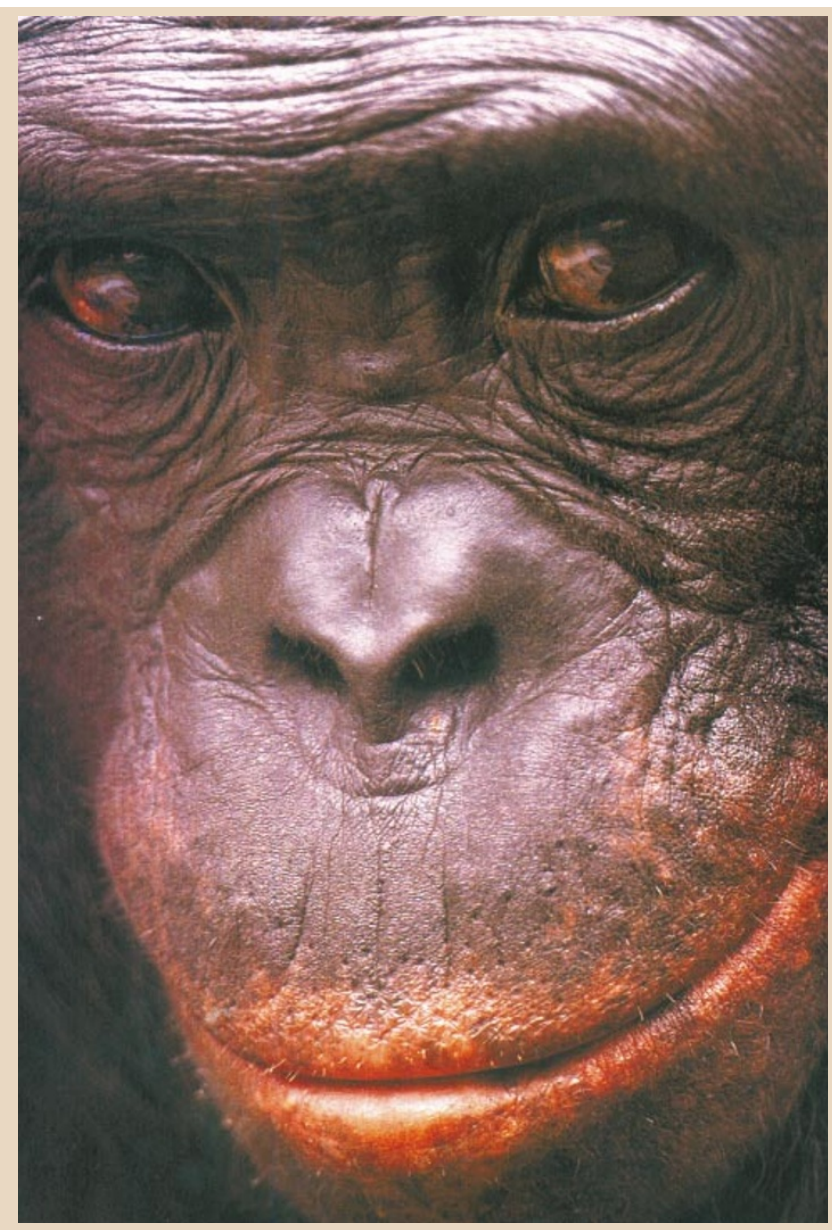

developmental biology predates the discovery of genetics by some centuries. Epigenetic alludes to genesis rather than genes.

Traditionally, epigenesis was the rival hypothesis to preformation - the view that the egg contains a tiny organism that grows in size rather than developing any new structures. The contrasting, epigenetic, view is that simple material components in the egg interact with their environment to produce a complex, functioning organism. Much of today's loose talk about genes as programs veers dangerously close to the preformation theory, and it is this danger that Rose warns us against. If we are still forced to flirt with preformation to get our minds around the fact that growth is a material process, then it is no surprise that we cannot imagine a material process giving rise to consciousness.

The inclusion of two papers by theologians - Nicholas Lash and Fraser Watts may seem unusual, but their concerns relate quite closely to other papers in the volume. Mary Midgley and William Clocksin both argue that the sciences of the mind must integrate the meaning of human action in its cultural context before they can hope to solve the problem of consciousness. Complementing these views, Watts makes an extended comparison of the relationship between consciousness and materiality with that between theology and science. Lash addresses some of the same difficult questions of identity using theological ideas developed to deal with the doctrine of the Trinity.

Bernard Balleine and Anthony Dickison's paper introduces another way in which the sciences of the mind might be enriched - by greater attention to the emotions. This idea featured in a recent conference, "Emotion, Consciousness and Qualia", convened by the consciousness studies programme of the University of Arizona at Tucson, whose seminal role Cornwell discusses in his introduction.

I was lucky enough to attend this meeting, where it became clear that many leading neuroscientific investigators of emotion, such as Joseph LeDoux, feel they can answer the important questions about the material basis of emotion without investigating the nature of emotion consciousness. They need not even take a stand on whether the states they investigate, such as states in the rat brain homologous to fear in the human brain, are conscious at all. This rather suggests that Lipton is right and that, if the neuroscience of emotion illuminates the problem of consciousness, it may only be because it helps advance the sciences of the mind, "leaving the identity question to torment philosophers".

Paul E. Griffiths is in the Unit for History and Philosophy of Science, Faculty of Science,

University of Sydney, New South Wales 2006, Australia. 